\title{
Statistical analysis on rolling contact fatigue in railroad axle bearing steel
}

\author{
Rubing Guo ${ }^{1}$ (D) Guangxue Yang ${ }^{1}$ | Zhengyang Li $^{2} \mid$ Zhiming Liu $^{1} \mid$ Yujie Wei ${ }^{1,2}$
}

\author{
${ }^{1}$ Key Laboratory of Vehicle Advanced \\ Manufacturing, Measuring and Control \\ Technology, Beijing Jiaotong University, \\ Beijing, China \\ ${ }^{2}$ LNM, Institute of Mechanics, Chinese \\ Academy of Sciences, Beijing, PR China
}

\section{Correspondence}

Yujie Wei, Key Laboratory of Vehicle Advanced Manufacturing, Measuring and Control, Beijing Jiaotong University, Beijing 100044, China.

Email: yujie_wei@Inm.imech.ac.cn

\section{Funding information}

National Key Research and Development Program of China, Grant/Award Numbers: 2016YFB1200501- 008 and 2016YFB1200503-C-03; Strategic Priority Research Program of the Chinese Academy of Sciences, Grant/Award Number: XDB22020200

\begin{abstract}
High-strength steels are widely used in high-performance bearings utilized in most mechanical systems. However, there has been little statistical analysis regarding the fatigue failure behaviour of the material, where surface peeling resulted from contact fatigue during rolling is a significant life-limiting mechanism. In this study, we examine the statistical behaviour of surface-crack nucleation, propagation, and peeling in a high-speed train axle bearing made of GCr15 steel by using a laboratory rolling-contact equipment. We reveal that cyclic rolling-contact leads to the formation of a hardness gradient in the outer ring of the bearing. The gradient layer is of several millimetres. The peeling rate could be as high as $28 \mu \mathrm{m}$ per million cycles when the contact pressure is close to that applied in real service. Peeling-induced cracking is dominantly transgranular. The incipient angle is about $23.2^{\circ}$, and its depth could be hundreds of micrometres. The findings reported here could be employed to assess the lifetime of bearings made of GCr15 steel and possible other engineering metals.
\end{abstract}

\section{KEYWORDS}

bearing steel, crack propagation, rolling contact fatigue, statistical analysis

\section{1 | INTRODUCTION}

Bearings are widely used to transmit rotary motion and to support radial and thrust loads. Axle bearing failure is a serious issue that may result in operation delays and even catastrophic accidents. It is broadly accepted that rolling contact fatigue (RCF) is the primary mechanism responsible for the failure of most bearings. Fatigue cracking may initiate from either the contact surface or subsurface, and cracks can be resulted from contaminated lubricants, or foreign particles entrained in the moving elements of the bearing produce wear or denting of the bearing surfaces. ${ }^{1}$ Several types of test methods are applied to evaluate the RCF of bearings, including the four-ball-rolling tester, ${ }^{2}$ the five-ball-rolling tester, ${ }^{3}$ the v-groove/ball tester, ${ }^{4}$ the rolling-element-on flat tester ${ }^{5}$

\footnotetext{
Nomenclature: $U_{\text {drive }}$, speed of drive roller; $U_{\text {driven }}$, speed of driven roller; $E_{1}$, Young's modulus of driven roller; $E_{2}$, Young's modulus of drive roller; $\nu_{1}$, Poisson ratios of driven roller; $\nu_{2}$, Poisson ratios of drive roller; $R_{1}$, radius of driven roller; $R_{2}$, radius of drive roller; $P$, load of contact line; $L$, length of contact line; $l$, crack length; $l_{1}$, crack extension length after one cycle; $r$, maximum half-width; $h_{0}$, crack opening displacement; $h_{1}$, crack opening displacement after one cycle; $a$, angle between the direction of frictional force and crack; $\dot{\alpha}$, angular opening velocity of crack; $\alpha_{0}$, crack growth angle; $\gamma$, deflection angle; $d_{1}$, crack depth; $d_{\max }$, maximum crack depth; $\mu$, friction coefficient; $p(x)$, hydrodynamic pressure; $\eta$, kinematic viscosity of bearing grease; $\rho$, density of grease; $F$, resultant force per unit length; $K_{\mathrm{I}}$, Mode I stress intensity factor; $K_{\mathrm{II}}$, Mode II stress intensity factor; $\tau_{\max }$, Maximum shear stress; $K_{\tau}(\gamma)$, stress intensity factor of shear stress; $K_{\sigma}(\gamma)$, stress intensity factor of tensile stress; $\Delta K_{\sigma t h}$, threshold of stress intensity factor; $\sigma_{y s}$, $0.2 \%$ offset yield stress; $w$, average grain size
} 
and the three-contact-point tester. ${ }^{6}$ Materials with distinct constitutive behaviour were considered by different groups $^{7-10}$ to connect the rolling behaviour with mechanical properties, in particular how the hardening behaviour of the materials would affect the RCF of those bearings. In those studies, the researchers paid more attention to the fatigue of ball bearings under point-contact conditions and obtained many valuable conclusions at the same time.

As reported by many groups, ${ }^{7,8,11,12}$ two fracture modes are identified in the fatigue process of high-strength steels under very-high-cycle fatigue. The first is the surface-induced fracture, and the second is the interior inclusion-induced fracture. The former mode tends to occur at higher stress levels, while the latter may appear even at lower stress levels. Liu ${ }^{13}$ noted that a fatigue crack initiates from the surface of a specimen in the low-cycle regime while starts from the inclusion in the interior of the specimen in very-high-cycle fatigue regime.

It is generally believed that local heterogeneities promote RCF by forming microcracks from the subsurface. The coalescence of these microcracks results in a macrocrack that propagates to the surface. Consequently, materials peel away from the surface. ${ }^{14}$ Given the statistical nature of the distribution of heterogeneities at the microscale, surface peeling is statistical in nature.

TABLE 1 The chemical composition of the high carbon chromium steel GCr15 (mass \%)

\begin{tabular}{lccccc}
$\mathbf{C}$ & $\mathbf{C r}$ & $\mathbf{M n}$ & $\mathbf{N i}$ & $\mathrm{Si}$ & Mo \\
0.98 & 1.35 & 0.39 & 0.16 & 0.30 & 0.05 \\
\hline
\end{tabular}

Therefore, it is of our interest to understand the statistical characteristics of cracks due to RCF, which could be employed for better lifetime assessment for these critical rolling components in advanced machine systems. In this paper, we choose the broadly used bearing material GCr15 steel for this investigation and present its statistical rolling contact fatigue behaviour.

\section{2 | MATERIAL PREPARATION AND EXPERIMENTAL METHODS}

The high carbon chromium steel GCr15 is used in the outer ring of bearings. Its phase composition is listed in Table 1 . We design a friction-and-wear testing machine to study the $\mathrm{RCF}$ of the material. The set-up of the testing system is shown in Figure 1A. In Figure 1B, we show the geometry of the specimen geometry. The two counterface rollers have a diameter of $45.4 \mathrm{~mm}$, and the final set-up is shown in Figure 1C. Load is transmitted to the counterface of the rollers by the spring system. The system allows for the applied load to be well controlled within the range of 0 to $1500 \mathrm{~N}$, with a resolution of $1 \mathrm{~N}$. An eddy current brake is employed on the driven disc side to control the slip ratio between the two rollers. All tests are conducted at a speed of $1200 \mathrm{r} /$ minute, corresponding to a line velocity of $200 \mathrm{~km} /$ hour. The slide-roll ratio, which is defined as $\left(U_{\text {drive }}-U_{\text {driven }}\right) / U_{\text {drive }}$, is set to $2 \%$. The friction coefficient between the driven and drive rollers is approximately 0.1 . When there is relative sliding between the two surfaces in contact, peeling is primarily seen in the driven surface. ${ }^{15}$ We will focus our observation on the driven roller.

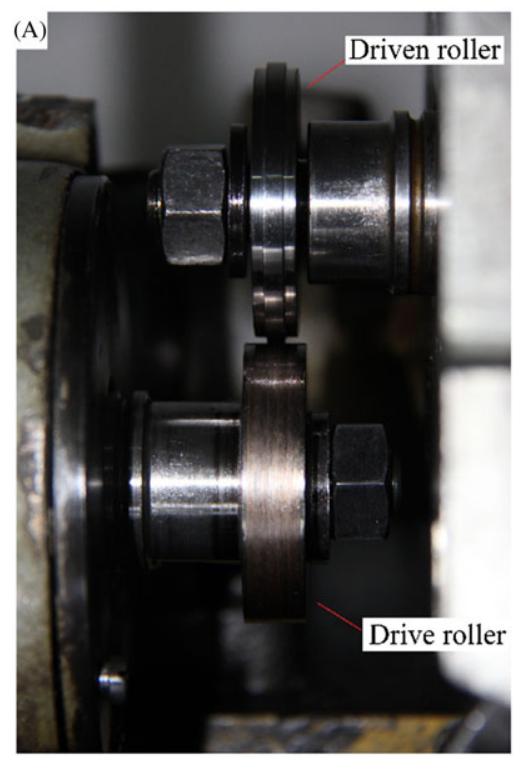

(B)

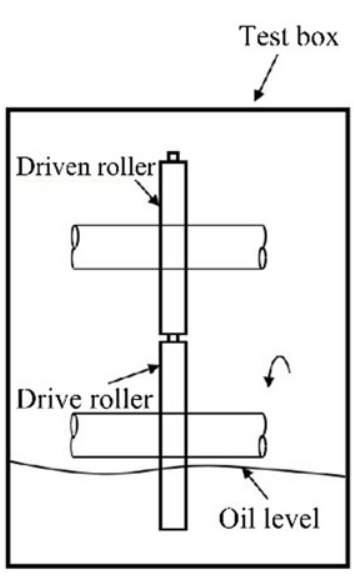

(C)

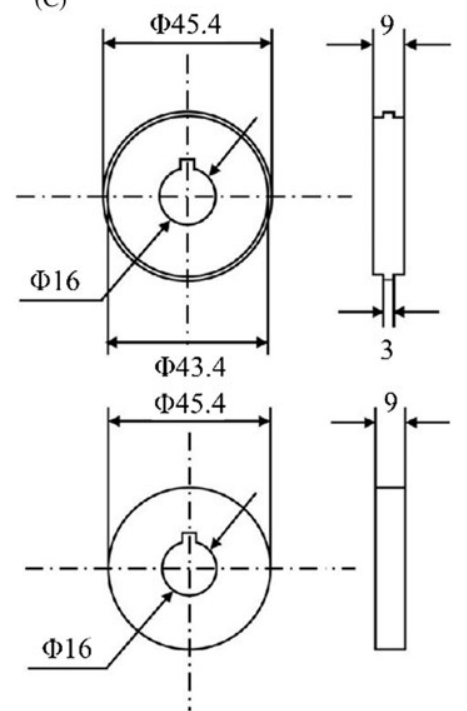

FIGURE 1 The assembly of the friction-and-wear testing machine. A, The contact system consists of a drive roller and a driven roller, and peeling is primarily seen on the driven surface. B, The testing system runs with lubricating oil. C, The fatigue samples machined from the same bearing of the HSR, and the exact dimensions [Colour figure can be viewed at wileyonlinelibrary.com] 


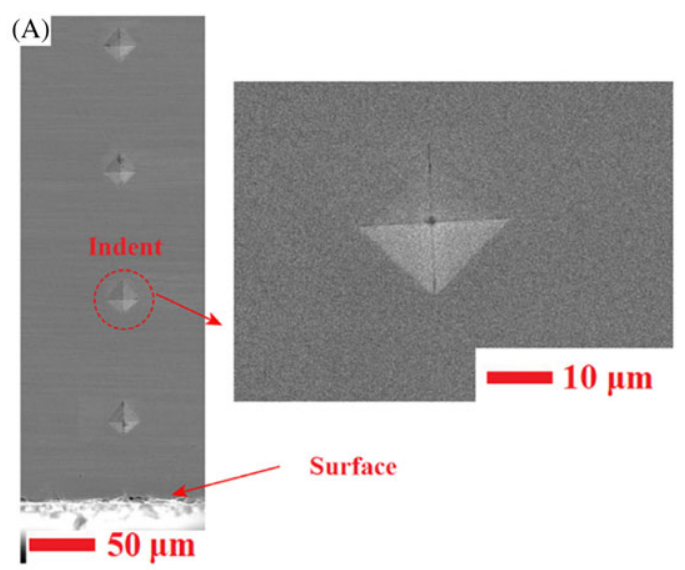

(B)
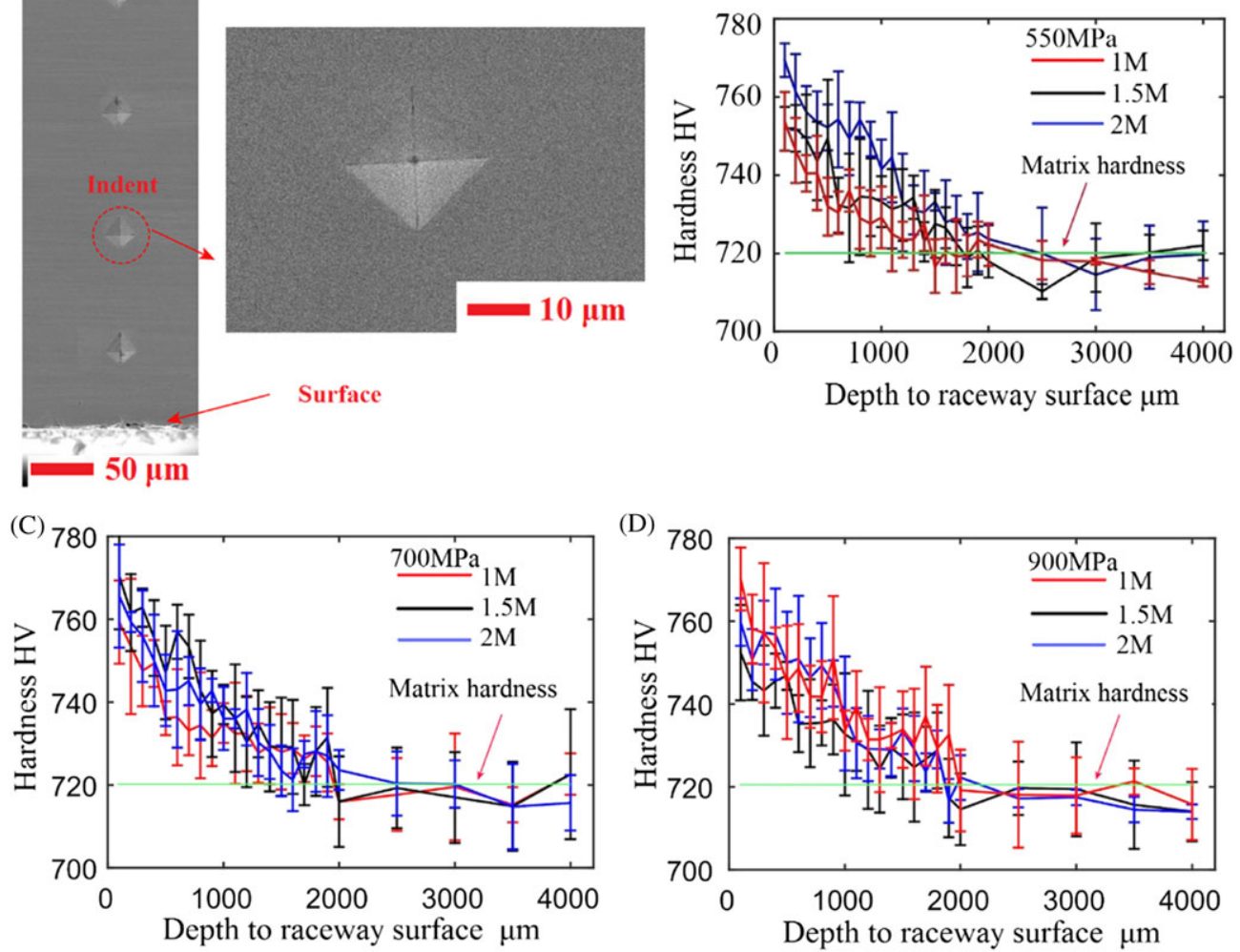

FIGURE 2 The indent distribution of the tested specimen and the hardness data distribution: A, SEM images of the indents and SEM image of the indent in red circle and B, to D, hardness distribution of the rollers subject to different nominal contact pressure of 550, 700, and $900 \mathrm{MPa}$, respectively. At each load, the hardness profiles at different duration of service $1 \times 10^{6}, 1.5 \times 10^{6}$, and $2 \times 10^{6}$ are shown [Colour figure can be viewed at wileyonlinelibrary.com]

Rolling contact fatigue testing usually takes a great deal of time. Ancellotti ${ }^{16}$ proposed a fluid entrapment model with fluid pressure inside the crack and found that lubricant is necessary to trigger crack propagation. $\mathrm{Li}^{17}$ proposed a rolling contact fatigue accelerating method with a small slip rate: (1) The samples are first run at a speed of $1200 \mathrm{r} /$ minute for 1 hour without lubrication while keeping the friction coefficient at approximately 0.4. (2) The test is then continued with lubricating oil and hence a lower friction coefficient of 0.1. The length of the contact zone is $3 \mathrm{~mm}$. Considering the actual load of the HSR bearing ${ }^{18}$ and the carrying capacity of the test equipment, we use three normal loads 560, 900, and $1400 \mathrm{~N}$ by adjusting the spring. These loads in turn produce a Hertz contact pressure of 550, 700, and $900 \mathrm{MPa}$, respectively. The specimen is lubricated using a temperature-controlled oil sump to keep the oil temperature constant $(300 \mathrm{~K})$.

\section{1 | Microhardness test}

The samples for the hardness measurements are sliced from the cross section of the fatigue samples, mechanically grinded using 5000-grade water sandpaper, and then polished to achieve a mirror-like surface. The Vickers hardness of the fatigue samples is measured by an MH-6 microhardness tester. The hardness is measured under a load of $300 \mathrm{~g}$ and a dwell time of 10 seconds at room temperature. Five different zones are taken from each sample and subjected to the hardness test. The measurements are conducted along the radial direction, with an indent spacing of $0.1 \mathrm{~mm}$ (see Figure 2A). The hardness distribution is then obtained from the recorded measurements.

For the X-ray diffraction (XRD) characterization, the contact surfaces are grinded mechanically using 5000-grade sandpaper and then mechanically polished by a diamond suspension to eliminate the mechanical scratches. After 2 million cycles, three contact pressure samples are selected for testing.

\section{2 | Peeling characterization and fatigue crack}

Scanning electron microscopy (SEM) combined with electron backscatter diffraction (EBSD) is used to 
evaluate the outer ring's peeling evolution. The specimen is examined after four different durations of service at $900 \mathrm{MPa}, 1 \times 10^{6}$ cycles, $2 \times 10^{6}$ cycles, $3 \times 10^{6}$ cycles, and $4 \times 10^{6}$ cycles. For the SEM micrograph observation of the peeling process, the samples are immediately washed with acetone in an ultrasonic cleaner, and wiped with a soft medical cotton ball, then flushed with absolute ethyl alcohol and dried in warm air. Surfaces in rolling contact in the specimen are observed to measure the rate of peeling extension via SEM. For the EBSD characterization, the sample subject to a nominal contact pressure of $900 \mathrm{MPa}$ for $2 \times 10^{6}$ cycles is chosen. The sample is grinded mechanically using 5000-grade sandpaper and then mechanically polished by a diamond suspension to eliminate the mechanical scratches. The mechanically polished surface of a sample is further polished in a colloidal silica suspension for 2 hours to yield a stress-free surface to achieve high-quality EBSD images. Afterwards, the sample is immediately flushed with running water, wiped with a soft tissue soaked with absolute ethyl alcohol, and dried in warm air. The SEM/EBSD characterization is performed on a JEOL 6500F test platform, which is equipped with HKL Channel 5 software for conducting crystallographic analyses at a $20 \mathrm{kV}$ accelerated voltage, $2.4 \mathrm{nA}$ beam current, and $70^{\circ}$ sample tilt. The step size is $0.05 \mu \mathrm{m}$, and a square scan grid is used.

\subsection{Statistics of rolling fatigue}

SEM is used to evaluate the crack propagation evolutions, and the samples are cut from the cross section of the specimen. For the cross-sectional observation, the samples are grinded mechanically using 5000-grade sandpaper and then mechanically polished by a diamond suspension. For the SEM micrograph observation of the crack propagation process, $1.5 \times 10^{6}$ cycles and $2 \times 10^{6}$ cycles at 550,700 , and $900 \mathrm{MPa}$ are chosen. All cracks longer than $10 \mu \mathrm{m}$ in the contact zone areas are counted from the SEM images.

\section{3 | RESULTS AND DISCUSSIONS}

\section{1 | Microhardness}

By using an MH-6 instrumented microhardness tester with a continuous stiffness measuring function, the microhardness of the cross sections of the fatigue specimens is measured. Its distribution is characterized as being a function of the depth from the surface, as shown in Figure 2B to D. Near the contact surface, the microhardness is approximately $770 \mathrm{HV}$ and the highest, and it then decreases to about $720 \mathrm{HV}$ at a depth of $\sim 2000 \mu \mathrm{m}$, which is close to the microhardness of the as-received bearing material.
The hardening behaviour in rolling contact has been investigated in steels for a long time. Voskamp ${ }^{19}$ mentioned that the bearing steel would lead to a steady-state condition after 1000 to 2000 revolutions. Guo ${ }^{1}$ studied bearing steels at different operation distances, and observed clear grain refinement and an inhomogeneous hardness distribution. Strengthening mechanisms in martensitic steel usually involve solid solution, dislocation, grain boundary, and precipitation strengthening. ${ }^{20-23}$ In the deformation zone with large depth, a large number of dislocation walls and dislocation entanglement structures are formed inside the martensite lath. As the depth of the surface decreases, more and more dislocations and dense dislocation walls develop in the martensite laths, and the resulted grain/cell size decreases gradually with increasing strain and strain rate. ${ }^{24}$ Subboundaries are formed due to reconstruction of highdensity dislocation walls; the original martensite laths are divided into small domains. ${ }^{25,26}$ Richman and Landgraf ${ }^{27}$ and Voskamp et $\mathrm{al}^{19,28}$ also suggested that the cyclic hardening of hardened steels was a consequence of the stressinduced transformation of retained austenite. Arakere et $\mathrm{al}^{29}$ mentioned that plastic strain accumulation around the carbide inclusions in bearing steel can result in a maximum steel hardness increase of approximately $12 \%$ after $\sim 13.5 \times 10^{6}$ cycles. Xie et $\mathrm{al}^{30}$ reported that the hardness of chrome molybdenum steel increases by approximately $50 \%$ in the contact surface zone area, owing to the local plastic work-hardening effect. Therefore, it is necessary to observe whether the material experiences phase transformation.

We present in Figure 3 the X-ray diffraction patterns for the contact surfaces of samples subject to different

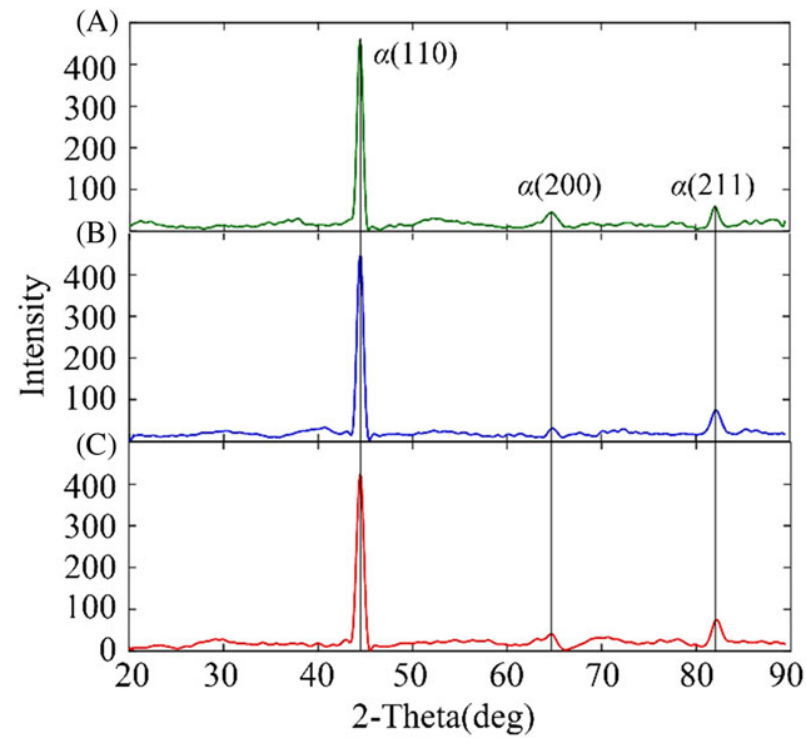

FIGURE 3 XRD pattern of materials subject to different contact pressure after $2 \times 10^{6}$ cycles: A, $550 \mathrm{MPa}, \mathrm{B}, 700 \mathrm{MPa}$, and C, $900 \mathrm{MPa}$ [Colour figure can be viewed at wileyonlinelibrary.com] 
nominal contact pressure of 550, 700, and $900 \mathrm{MPa}$. The $\mathrm{X}$-ray diffraction patterns reveal that the phase structure of the bearing materials is mainly body-centred cubic (BCC) martensite, with no identifiable peaks of retained austenite at different contact stress levels and at different duration of service, as shown in Figure 3. Hence, we conclude that the bearing steel hardening may result primarily from dislocation-induced work hardening as there is no change in the phase structure.

\section{2 | Crack propagation and peeling morphology}

The micrographs in Figure 4A and 4B show examples of typical surface-initiated peeling found on the roller contact fatigue specimen. Typical patterns of crack propagation across the surface are illustrated by the SEM images, as shown in Figure $4 \mathrm{C}$ to E. It can be seen that crack growth prefers to the frictional force direction. Pawel ${ }^{31}$ found that visible cracks have an initial angle of inclination to the surface of $20^{\circ}$ to $30^{\circ}$ in bearing steel. Deng ${ }^{32}$ noticed that the crack propagation could be divided into two phases: First, the crack propagates obliquely downward from the bearing raceway surface with an approximate inclination angle of $30^{\circ}$ relative to the raceway surface. Second, after the crack propagates to a certain depth, it changes direction and grows towards the surface and possible crack branching. At the end, a piece of the material may be removed, leaving behind a pit in the surface. In our study, the crack propagates downward in the contact zone and then towards the specimen surface.

In order to obtain peeling rate, we choose a typical peeling position to record the extension process at different cycles, as illustrated in Figure 5. The peeling length shown in Figure 5A to 5D is, respectively, 65, 84, 108, and $150 \mu \mathrm{m}$. The peeling rate is estimated to be $19 \mu \mathrm{m}$ per million cycles $(\mu \mathrm{m} / \mathrm{M}), 24 \mu \mathrm{m} / \mathrm{M}$, and $42 \mu \mathrm{m} / \mathrm{M}$, from 1 million cycles to 4 million cycles in turn. The average growth rate is about $28 \mu \mathrm{m} / \mathrm{M}$. We track about 110 peeling cracks from our SEM images, and the comprehensive statistic information is shown in Figure 6. The average rate of peeling extension is stable at approximately $28 \mu \mathrm{m} / \mathrm{M}$ cycles. The peeling extension rate does not change as the number of fatigue cycles increases.

To investigate the orientations of the grains near the crack, EBSD investigations are conducted. In addition to grain orientation investigations, the aim of EBSD analyses is to describe the strain distributions in those areas and their influence on microcrack initiation. ${ }^{33}$ In Figure 7 , we present two different zones to illustrate the crack propagation path. Areas 1-1 and 1-2 in Figure 7A depict the
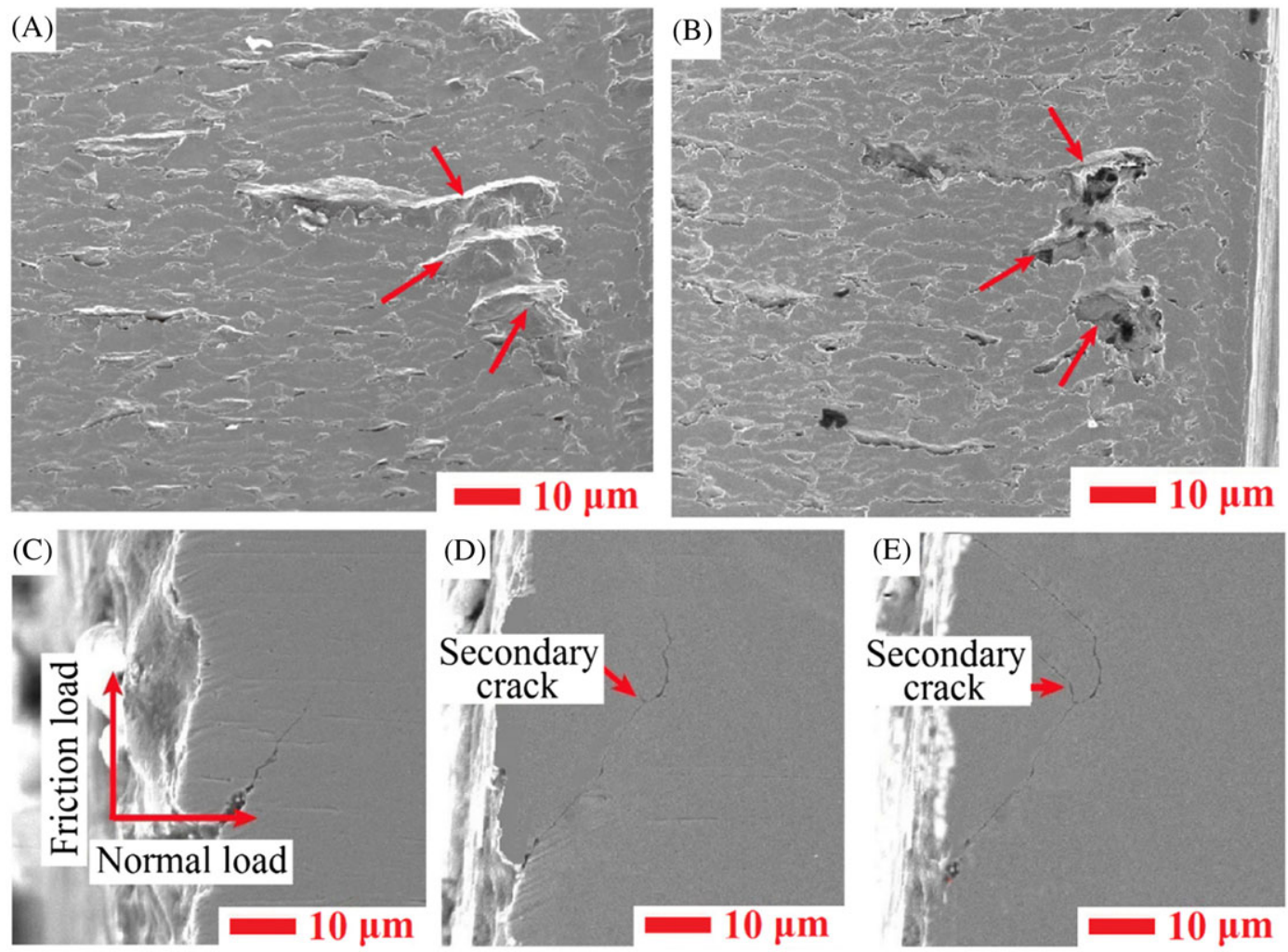

FIGURE 4 SEM images of a typical surface crack undergoing propagation and peeling at the nominal contact stress of 900 MPa but different duration: A, $1 \times 10^{6}$ cycles and B, $1.5 \times 10^{6}$ cycles. C, D, and E, show the growing process, kinking and branching, and peeling of a surface crack [Colour figure can be viewed at wileyonlinelibrary.com] 

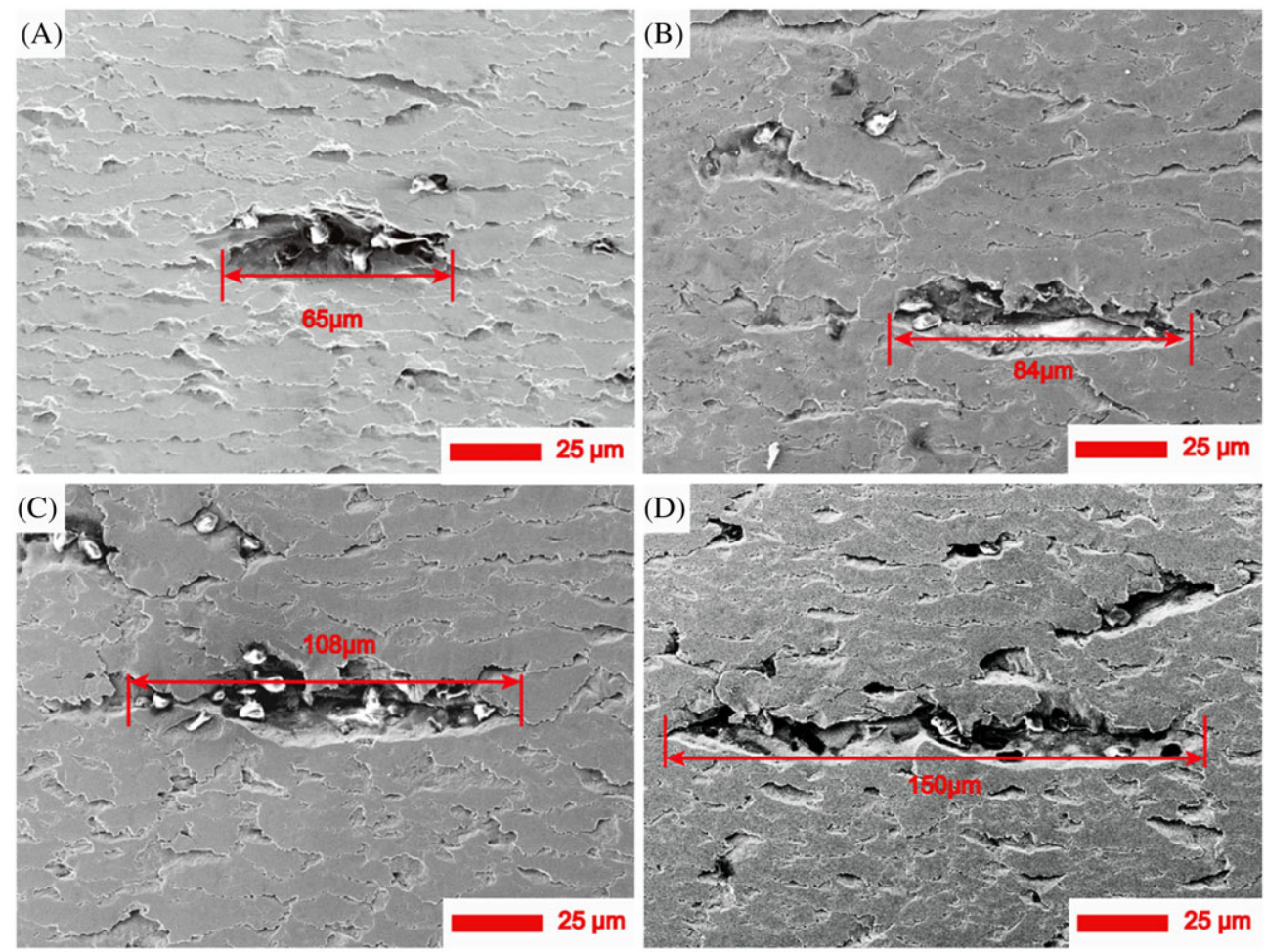

FIGURE 5 SEM images of a typical peeling process at different duration of service in the sample subjected to a nominal contact stress of $900 \mathrm{MPa}$ : A, $1 \times 10^{6}$ cycles, B, $2 \times 10^{6}$ cycles, C, $3 \times 10^{6}$ cycles, and D, $4 \times 10^{6}$ cycles [Colour figure can be viewed at wileyonlinelibrary.com]
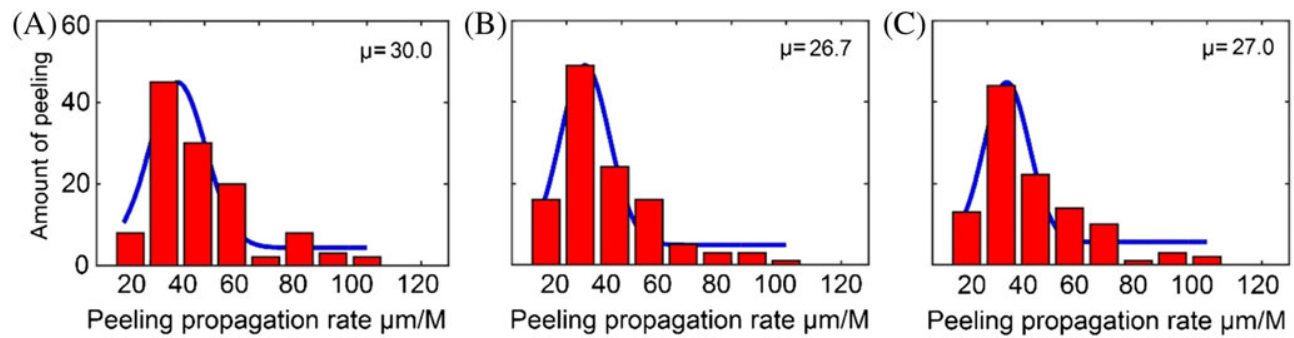

FIGURE 6 The results for different peeling propagation rates over different service duration: A, $1 \times 10^{6}$ cycles to $2 \times 10^{6}$ cycles, B, $2 \times 10^{6}$ cycles to $3 \times 10^{6}$ cycles, and C, $3 \times 10^{6}$ cycles to $4 \times 10^{6}$ cycles. From (A) to (C), we observe that the rate of peeling propagation is stable, having no clear connection with the number of cycles [Colour figure can be viewed at wileyonlinelibrary.com]

middle and tail of the crack. Their corresponding amplified SEM images are shown in Figure 7B and 7C. The legible zones in the map correspond to areas with excellent initial EBSD pattern quality, whereas the dark zones are regions with poor EBSD pattern quality. The poor quality is usually associated with severe lattice distortions or an increase in dislocation density. The principal crack propagates across the prior austenite grain in the middle area in Figure 7D. However, the crack propagates along the prior austenite grain at the tail of the crack in Figure 7E. Okazaki et $\mathrm{al}^{34}$ reported that a crack propagates along the prior austenite grain and/or packet boundary under low stress and that it propagates in the prior austenite grain and/or packet boundary under high stress.

We show in Figure 8 that a principal crack propagates into the prior austenite grain. Here, we focus on the second cracks, as seen in Figure 8A to 8C. Secondary cracks are observed to branch off the main crack and grow towards the surface, eventually liberating a fragment of the material and creating a pit formation. ${ }^{31}$ The secondary crack propagates into the prior austenite grain in Figures 7D and $8 \mathrm{C}$ but along the prior austenite grain in Figure 7E. The propagation direction of the secondary cracks is related to the main crack in the same area. The growth of secondary branching cracks shows a potential peeling mechanism, as the secondary cracks have been observed to propagate to the surface, liberating a fragment of the material (see Figure 4). Lankford ${ }^{35}$ studied the growth of short cracks in a martensitic high-strength steel and demonstrated that crack arrest occurred at prior austenite grains. However, Lankford did not focus on the microstructure around the crack. Many spheroidal cementite particles appear at the crack tip in 

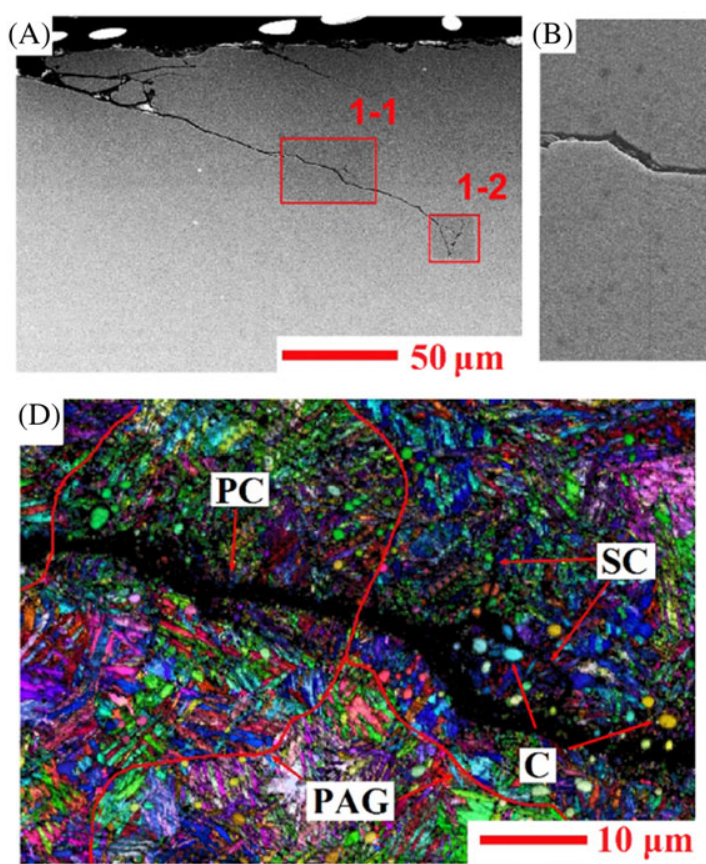
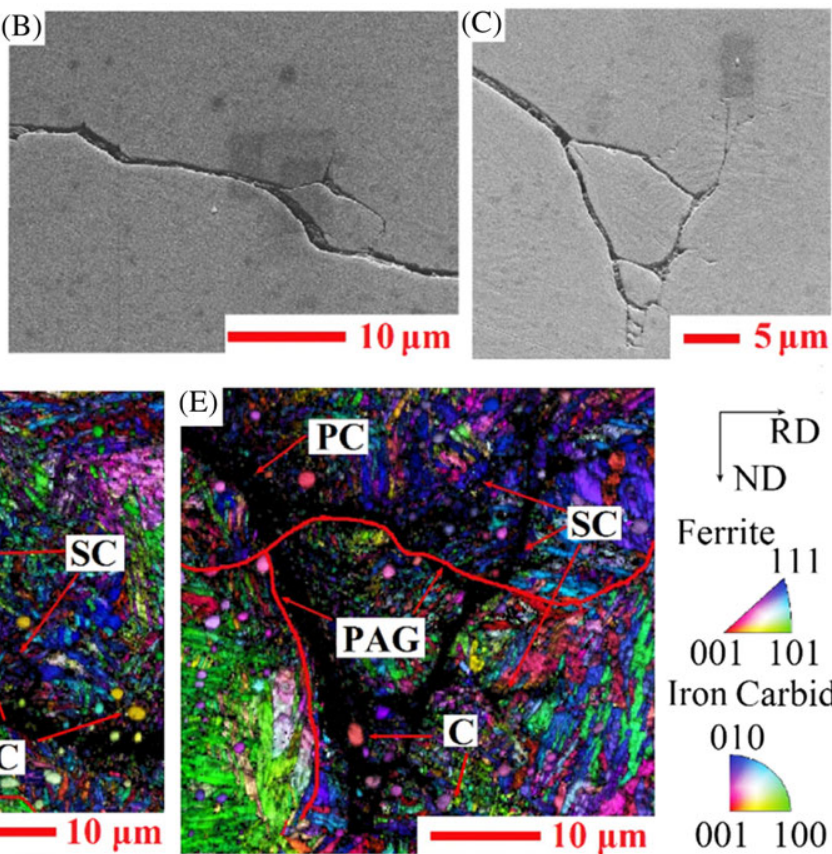

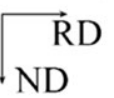

Ferrite

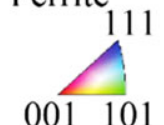

Iron Carbide

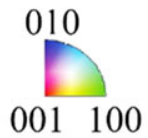

FIGURE 7 Scanning electron microscopy images and microstructure characterization from an EBSD analysis of a cross section of the 900 MPa sample. A, SEM image of the longest crack. B, SEM image of red box (1-1) in A. C, SEM image of red box (1-2) in A. D, EBSD map with IQ map of red box (1-1) in A. E, EBSD map with IQ map of red box (1-2) in A. Red lines represent prior austenite grain boundaries; oval particles represent cementite. Abbreviations: PC, principal crack; SC, secondary crack; PAG, prior austenite grain; C, cementite; RD, rolling direction; ND, normal direction). From (D) and (E), we see that the primary cracks primarily resulted from a transgranular fracture, while an intergranular fracture played the primary role for the secondary cracking stage [Colour figure can be viewed at wileyonlinelibrary.com]
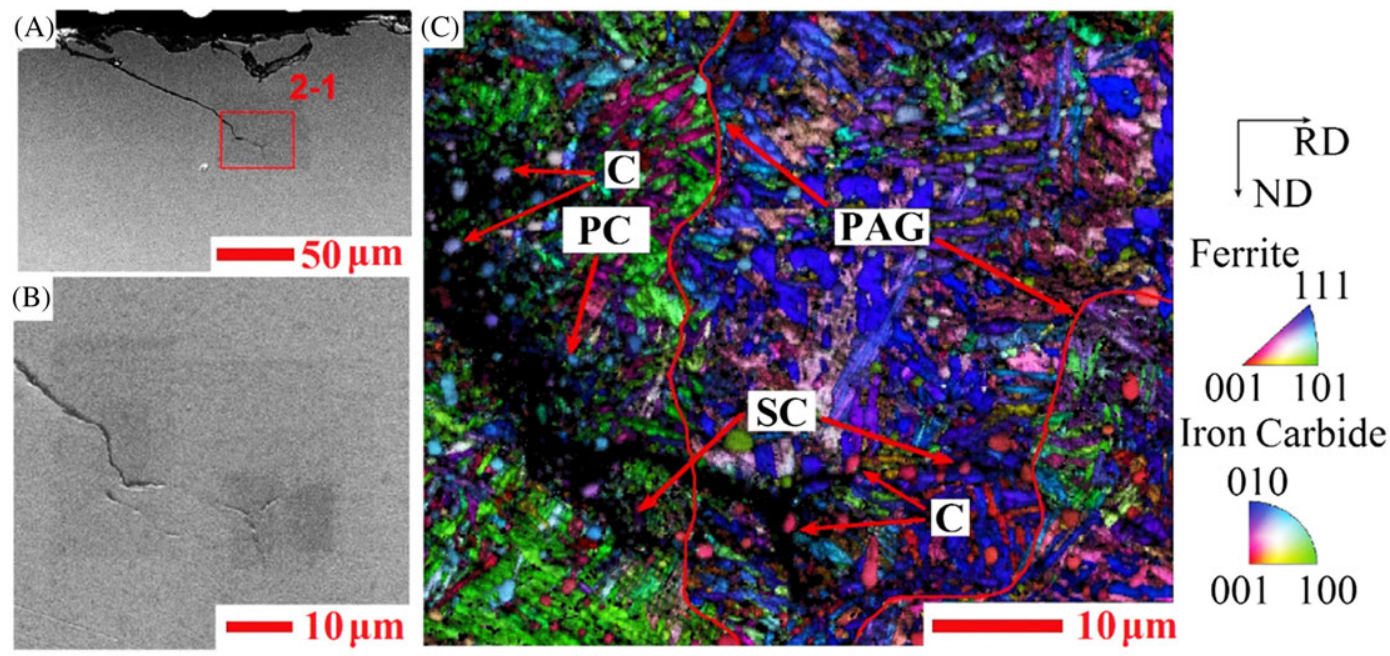

FIGURE 8 SEM images and microstructure characterization from an EBSD analysis of a cross section of the 900 MPa sample. A, SEM image of the crack. B, SEM image of red box (2-1) in A. C, EBSD map with IQ map of red box (2-1) in A [Colour figure can be viewed at wileyonlinelibrary.com]

Figures 7D, 7E, and $8 \mathrm{C} . \mathrm{Li}^{36}$ reported the occurrence of a fracture at the interfaces of martensite-cementite related to the dissolution and coarsening of cementite particles. Bhadeshia $^{37}$ mentioned that a considerable amount of deformation occurred around the cementite, which has been shown to adversely affect the RCF life in accelerated tests. $^{38}$ Only high density carbide particles may effectively prevent crack propagation. ${ }^{39}$ As a resultant of plastic deformation, the microvoids are formed in the interface between the cementite and the matrix, and they then develop to the secondary crack. The propagation direction of principal and secondary cracks has a relationship with the shear stress. Principal and secondary cracks always extend through the prior austenite grain near the contact area with high shear 
stress. When a crack reaches a certain depth, it expands along the prior austenite grain due to the decrease in shear stress. Meanwhile, the cracks prefer to propagate towards the cementite-intensive area where its fracture toughness is low.

\section{3 | Rolling fatigue crack statistics}

A typical crack is shown in Figure 9, where $a$ is the angle between the direction of the frictional force and the crack and $l$ is the length of the crack. The maximum half-width $r$ for two elastic bodies in linear contact is given by the following equation ${ }^{40,41}$ :

$$
r=\left(\frac{4 P}{\pi L} \frac{\frac{1-v_{1}^{2}}{E_{1}}+\frac{1-v_{2}^{2}}{E_{2}}}{\frac{1}{R_{1}}}+\frac{1}{R_{2}}\right)^{1 / 2}
$$

where $P$ and $L$ are the load and length of the contact line, respectively, $R_{1}$ and $R_{2}$ are the radius of the contact rollers, $E_{1}$ and $E_{2}$ are the moduli, and $\nu_{1}$ and $\nu_{2}$ are the Poisson ratios. Here, $R_{1}=R_{2}=22.7 \mathrm{~mm}, E_{1}=E_{2}=210 \mathrm{GPa}$, $\nu_{1}=\nu_{2}=0.3$. We then obtain $r=0.25 \mathrm{~mm}$ from Equation 1. Aditya ${ }^{42}$ noted that spalls initiated deeper in the domain for cases of lower depths and that the initiation occurred around the half-width area below the surface, where the shear stress maximizes. Hence, our observation will be focused on the contact area in the test.

Figure 10 shows the relationship between the crack angle and the number of fatigue cycles counted in a series of experiments. To generalize and compare the results of the different tests, all cracks in the contact zone are counted in each test. The mean value of the crack growth angle is approximately $20^{\circ}$ to $33.2^{\circ}$, which is consistent with the theoretical calculations (between $15^{\circ}$ and $\left.30^{\circ}\right) .{ }^{15}$ Smith $^{43}$ and Timoshenko ${ }^{44}$ gave the stress distribution generated by concentrated loads in a Cartesian coordinate, from which we obtain the crack growth angle to be $\alpha_{0}=23.2^{\circ}$ as $\tan 2 \alpha_{0}=\frac{1-\mu}{1+\mu}=0.429$.

The relationship between the crack length and number of fatigue cycles is shown in Figure 11. It is apparent that the crack statistics follow a Weibull distribution in our tests. The average crack length is approximately 18, 30, and $47 \mu \mathrm{m}$ at 550, 700, and $900 \mathrm{MPa}$, respectively. The number of cracks generally increases as the number of cycles increases at a high stress level. It is also evident that the effect of the contact pressure is to increase the propagation.

Figure 12 gives the fatigue crack-length distribution at $900 \mathrm{MPa}$. We see that the crack length increases with the number of cycles from Figure 12A to C. However, the number and length of cracks decrease significantly after 2 million cycles. The amount of peeling is rechecked via SEM. Peelings are seen after 2 million cycles. Crack branching has been associated with rolling contact fatigue cracks in rolling bearings ${ }^{45}$ and it has been previously considered to cause peeling under rolling contact. ${ }^{46,47}$ As we all know, fatigue crack damage mainly consists of crack initiation, propagation, and fracture. In sharp contrast with the stage of propagation, the crack fracture growth rate increases rapidly. In this phase, the remaining $15 \%$ of the total life is devoted to pitting. In the final stages, the pit formation exhibits a large growth rate of approximately $50 \mathrm{~mm}$ per million cycles. ${ }^{31}$ As the experiment progresses, fatigue cracks appear in the bearing material after a certain number of cycles, and after 2 million cycles, the amount of peeling increases significantly.

To obtain the final crack length shown in Figure 9B, we derive the critical state for crack deflection in mixed mode. Endo ${ }^{48}$ and Tzou $^{49}$ derived an expression for crack

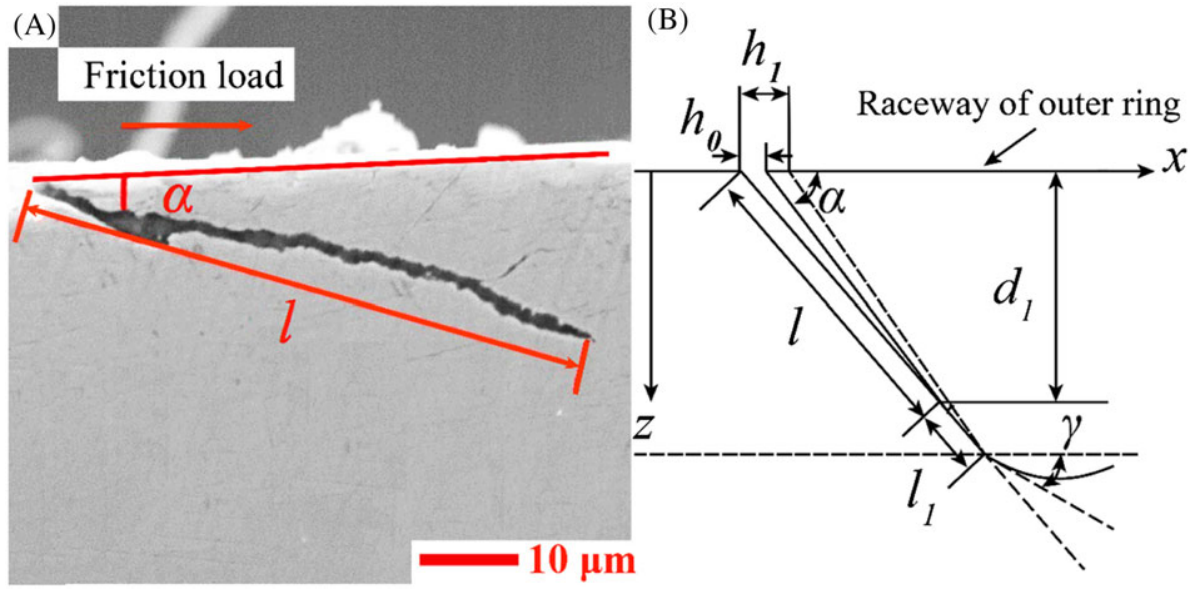

FIGURE 9 A RCF crack. A, SEM image of an RCF crack. B, Schematic of the crack propagation at different stages. The initial crack with length $l$ has an opening displacement (COD) of $h_{0}$. The COD becomes $h_{1}$ when the crack length becomes $l+l_{1}$ after one cycle. When the crack reaches a certain depth, it will kink by an angle $\gamma$ [Colour figure can be viewed at wileyonlinelibrary.com] 

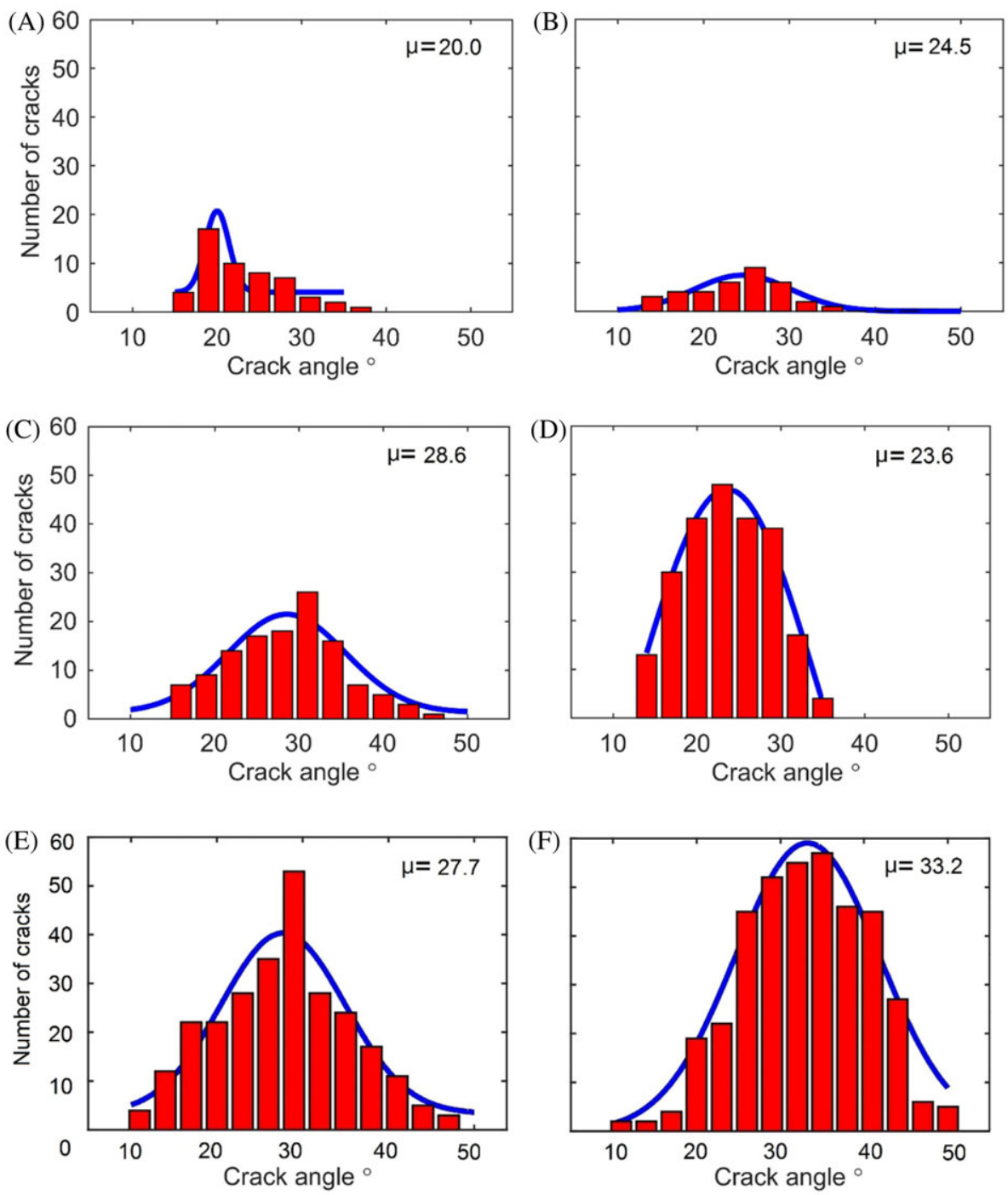

FIGURE 10 Fatigue crack angle distribution at different loads: A, $1.5 \times 10^{6}$ cycles at $550 \mathrm{MPa}, \mathrm{B}, 2 \times 10^{6}$ cycles at $550 \mathrm{MPa}$, C, $1.5 \times 10^{6}$ cycles at $700 \mathrm{MPa}, \mathrm{D}, 2 \times 10^{6}$ cycles at $700 \mathrm{MPa}, \mathrm{E}, 1.5 \times 10^{6}$ cycles at $900 \mathrm{MPa}$, and F, $2 \times 10^{6}$ cycles at $900 \mathrm{MPa}$ [Colour figure can be viewed at wileyonlinelibrary.com]

propagation in the presence of hydrodynamic pressure, which is described as

$$
p(x)=\frac{6 \eta \rho l^{3} \lg \left(1-\frac{x}{l}\right) \dot{\alpha}}{h_{1}^{3}}
$$

where $\eta$ is the kinematic viscosity of the bearing grease and $\eta=85 \times 10^{-6} \mathrm{~m}^{2} /$ second, $\rho$ is the density of the grease, $\rho=0.9 \times 10^{3} \mathrm{~kg} / \mathrm{m}^{3}, l$ is the crack length, and $\dot{\alpha}$ is the angular opening velocity of the crack. It may be related to $l_{1}$ (see Figure 9B) via $l_{1}=\frac{0.4 d_{1}}{\sin \alpha} \cdot{ }^{49}$ Now the crack growth rate is given as $\frac{d l_{1}}{d t}=\frac{0.4 d_{1} \cos \alpha}{\sin ^{2} \alpha} \dot{\alpha}$. By substituting the crack angular opening velocity into Equation 2, we obtain the fluid pressure as follows:

$$
p(x)=\frac{15 \eta \rho l^{3} \lg \left(1-\frac{x}{l}\right)}{h_{1}^{3}} \frac{\sin ^{2} \alpha}{d_{1} \cos \alpha} \frac{d l_{1}}{d t}
$$

Then, the resultant force (per unit length) can be obtained from the integration of pressure as follows:

$$
F=\int_{0}^{l} p(x) d x=\frac{15 \eta \rho l^{4} \sin ^{2} \alpha}{\ln 10 h_{1}^{3} d_{1} \cos \alpha} \frac{d l_{1}}{d t}
$$

The two terms $\frac{d l_{1}}{d t}$ and $h_{1}$ are obtained from the experiments: From Figure 12A and C, we see that the sample subject to $900 \mathrm{MPa}$ contact stress has an average crack length about $30 \mu \mathrm{m}$ within $1 \times 10^{6}$ cycles and $50 \mu \mathrm{m}$ within $2 \times 10^{6}$ cycles, which leads to $\frac{d l_{1}}{d t} \approx 4 \times 10^{-10} \mathrm{~m} / \mathrm{s}$ econd; to calculate $h_{1}$, we count 195 cracks from our 


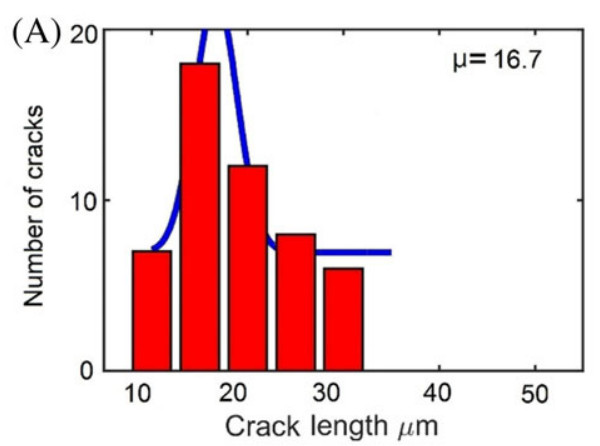

(B)
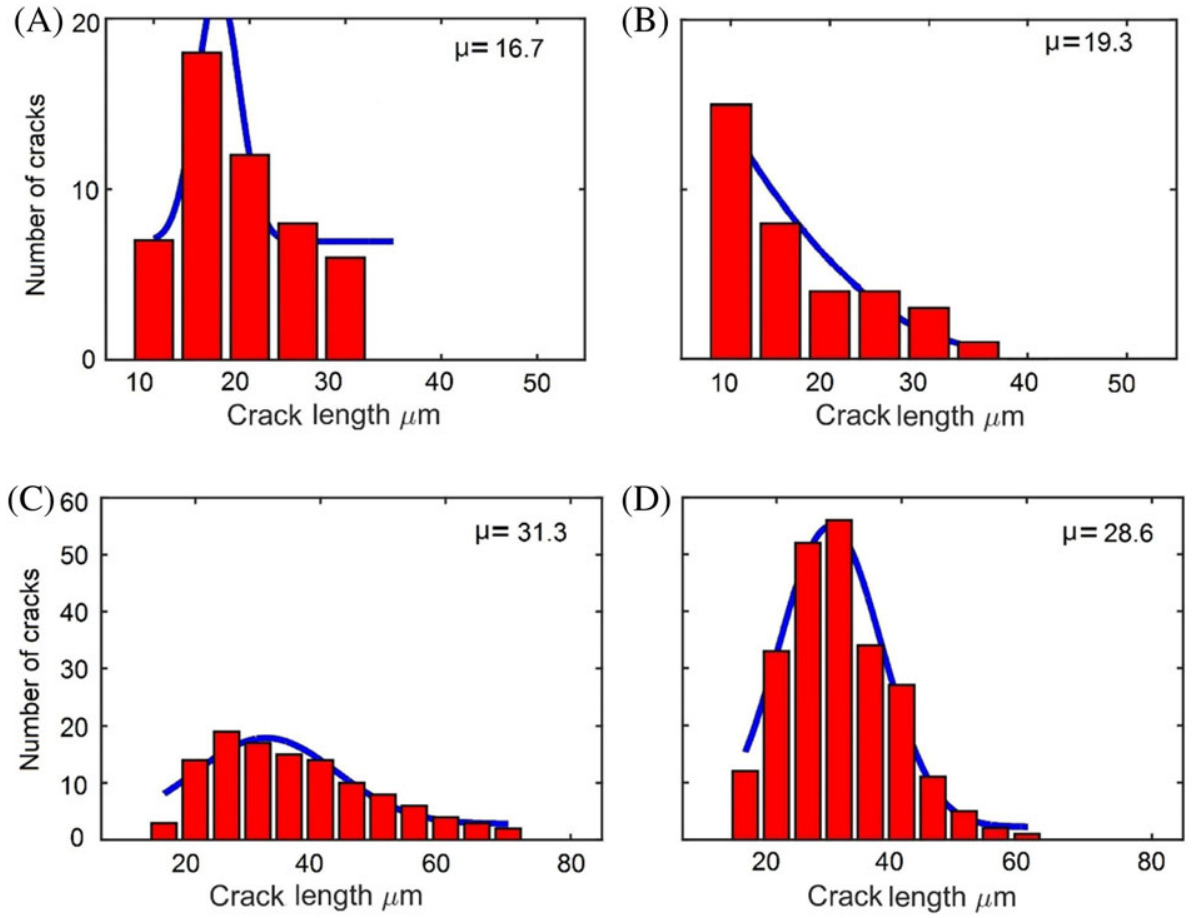

(D)

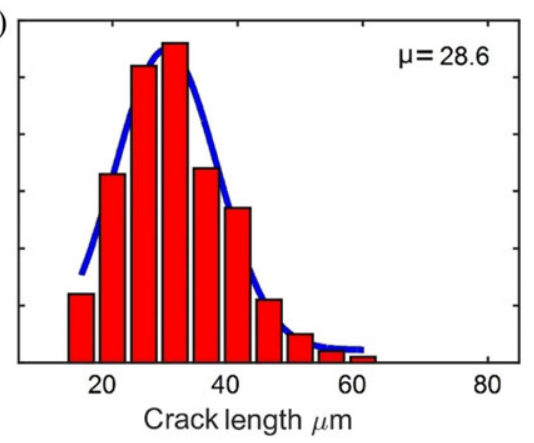

(F)

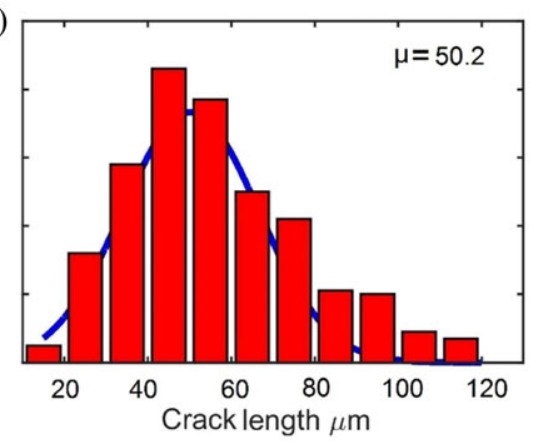

FIGURE 11 Fatigue crack length distribution at the same cycle number but different nominal contact pressure: A, $1.5 \times 10^{6}$ cycles at $550 \mathrm{MPa}, \mathrm{B}, 2 \times 10^{6}$ cycles at $550 \mathrm{MPa}, \mathrm{C}, 1.5 \times 10^{6}$ cycles at $700 \mathrm{MPa}$, D, $2 \times 10^{6}$ cycles at $700 \mathrm{MPa}, \mathrm{E}, 1.5 \times 10^{6}$ cycles at $900 \mathrm{MPa}$, and F, $2 \times 10^{6}$ cycles at $900 \mathrm{MPa}$ [Colour figure can be viewed at wileyonlinelibrary.com]

SEM images; the comprehensive statistic information is shown in Figure 13. The COD is about $h_{1}=1.5 \times 10^{-6} \mathrm{~m}$.

$\mathrm{Sih}^{50}$ calculated the approximate mode I stress intensity factor (SIF) due to the presence of these resultant forces by fluids:

$$
K_{I}=\frac{5.12}{\sqrt{\pi l}} F
$$

According to Equations 4 and 5, the mode I SIFs is rewritten as follows:

$$
K_{I}=\frac{18.82 \eta \rho l^{3.5} \sin ^{2} \alpha}{h_{1}^{3} d_{1} \cos \alpha} \frac{d l_{1}}{d t}
$$

and mode II SIFs is given as follows:

$$
K_{I I}=1.12 \tau_{\max } \sqrt{\pi l}
$$

A thorough theoretical analysis and corresponding numerical calculations of crack rotating direction have been given by Rice ${ }^{51}$ and Zeng. ${ }^{52}$ The deflection angle is given as follows:

$\gamma=\operatorname{acos}\left(\frac{3 K_{I I}^{2}+\sqrt{K_{I}^{4}+8 K_{I}^{2} K_{I I}^{2}}}{K_{I}^{2}+9 K_{I I}^{2}}\right)$ for $K_{I}>0$ and $K_{I I}>0$

Following Erdogan and Sih, ${ }^{53}$ the SIFs which represent the intensities of the fields of shear stress $K_{\tau}(\gamma)$ and tensile stress $K_{\sigma}(\gamma)$ near the crack tip are expressed by the following formulas:

$$
K_{\tau}(\gamma)=\frac{1}{2} \cos \frac{\gamma}{2}\left[K_{I} \sin \gamma+K_{I I}(3 \cos \gamma-1)\right]
$$



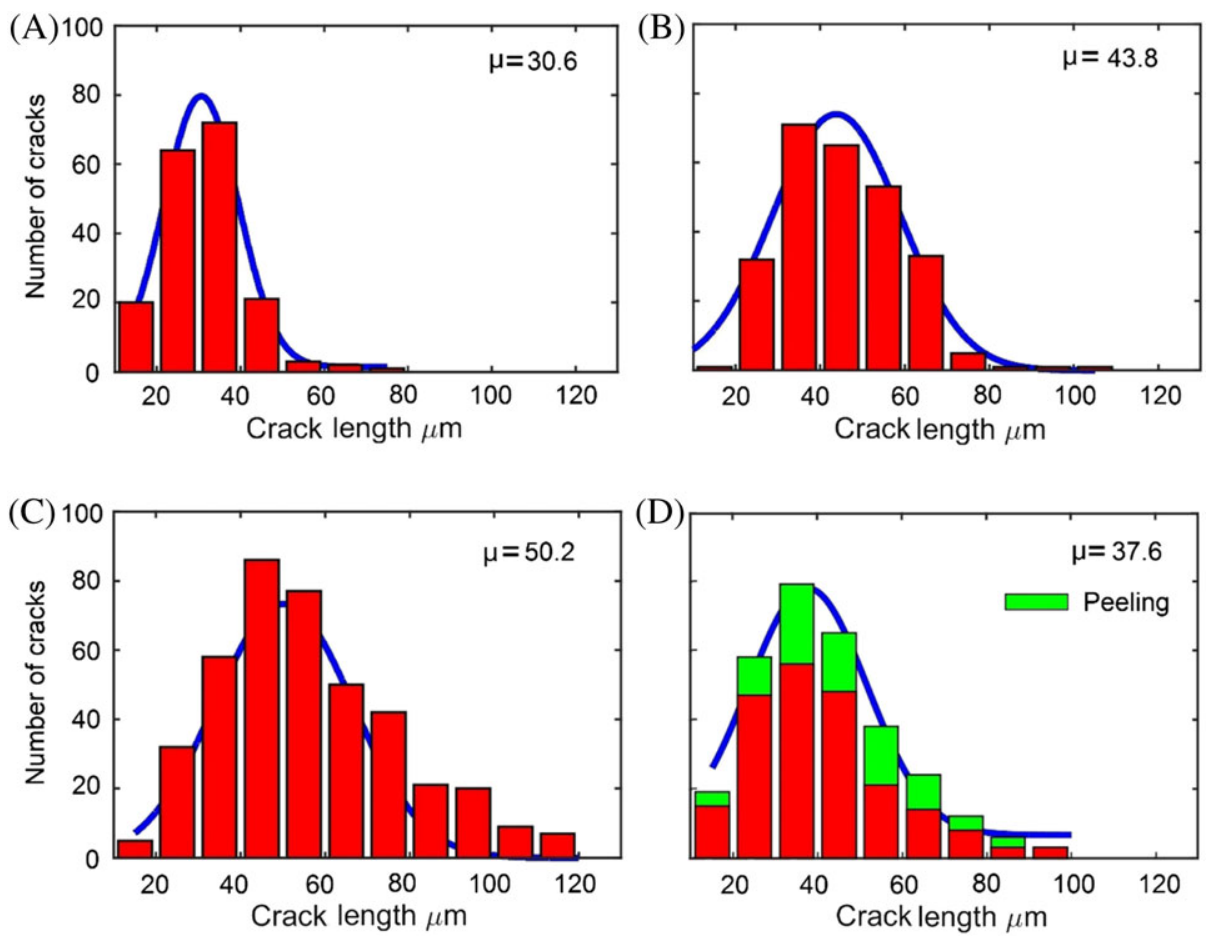

FIGURE 12 Fatigue crack length distribution at different cycles in the sample subjected to $900 \mathrm{MPa}$ : A, $1 \times 10^{6}$ cycles, B, $1.5 \times 10^{6}$ cycles, C, $2 \times 10^{6}$ cycles, and D, $4 \times 10^{6}$ cycles. The green part indicates the amount of peeling. From D, we observe that peeling occurs heavily after $2 \times 10^{6}$ cycles at $900 \mathrm{MPa}$ [Colour figure can be viewed at wileyonlinelibrary.com]

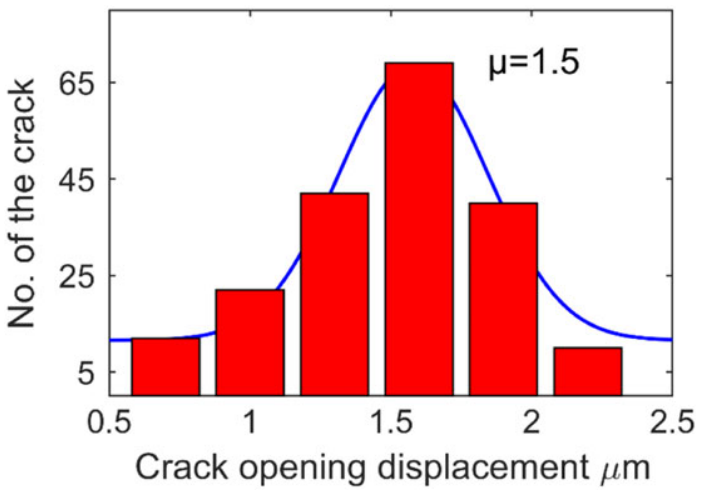

FIGURE 13 Fatigue COD distribution at 2 million cycles in the sample subjected to a nominal contact stress of $900 \mathrm{MPa}$ [Colour figure can be viewed at wileyonlinelibrary.com]

$$
K_{\sigma}(\gamma)=\cos \frac{\gamma}{2}\left[K_{I} \cos ^{2} \gamma-\frac{3}{2} K_{I I} \sin \gamma\right]
$$

Both the critical condition and the direction of crack growth were determined by the same criterion in Equations $8 \mathrm{~A}$ and $8 \mathrm{~B} .{ }^{46}$ The critical conditions in both the tensile mode fatigue crack growth and the transition from shear mode to tensile mode is given by $K_{\sigma}(\gamma) \geq \triangle K_{\sigma t h}$, where $\triangle K_{\sigma t h}$ is the threshold SIF.
Combining the results of Taira et $\mathrm{al}^{54}$ and Mutoh et $\mathrm{al},{ }^{55}$ the threshold SIF is given as follows:

$$
\triangle K_{\sigma t h}=5.5 \sigma_{y s} \sqrt{w}=7.92 M P a \cdot \sqrt{m}
$$

where the yield stress and the average grain size (shown in Figure 7) are $\sigma_{y s}=1.8 \mathrm{GPa}$ and $w=0.64 \mu \mathrm{m}$, respectively.

With Equations 6, 7, 8B, and 9, we obtain the critical length of a crack $l=0.288 \mathrm{~mm}$, and the corresponding maximum depth $d_{\max }$ the crack may reach is $d_{\max }=l \sin \alpha_{0}=0.114 \mathrm{~mm}$. At this depth, the crack kinks and starts to propagate to the surface, and eventually leads to peeling. The estimated crack size and peeling depth are consistent with experimental observations in the rolling test, as seen in Figures 7A and 12.

\section{4 | CONCLUSIONS}

Axle bearings play an extremely important role in highspeed rail (HSR) safety. Nevertheless, there have been few experimental studies on railway axle box bearing materials, in particular from the statistics aspect. This study is motivated to investigate the microstructure evolution and the peeling statistics of bearing materials under rolling contact fatigue. We perform rolling contact 
fatigue tests to GCr15 bearing steel using a twocounterface roller test rig. The following observations are obtained in this study: ( $a$ ) Contact rolling results in a hardness gradient in GCr15 bearing steel. The depth of the hardened region is about $2000 \mu \mathrm{m}$. The hardening mainly results from grain refinement and plastic work hardening, other than phase transformation. (b) A crack propagates downward from the contact surface at about $23.2^{\circ}$, which is determined by the maximum shear stress. When a crack reaches a maximum depth, it will kink and grow towards the surface, leaving behind a peeling in the contact surface. Both the critical crack length and the maximum depth could be calculated using classic fracture mechanics by taking the fluid pressure into account. (c) Principal and secondary cracks propagate across the prior austenite grain in the high-shear-stress zone, and are dominantly intergranular. The cracks propagate along the prior austenite grain when they reach a certain depth, and then prefer to propagate towards the cementiteintensive area and become transgranular. $(d)$ The crack growth angle is approximately $20^{\circ}$ to $33.2^{\circ}$, and the number of cracks generally increases with the number of cycles.

\section{ACKNOWLEDGEMENTS}

The authors acknowledge support from the Strategic Priority Research Program of the Chinese Academy of Sciences (XDB22020200) and the National Key Research and Development Program of China (2016YFB1200503-C-03 and 2016YFB1200501-008).

\section{ORCID}

Rubing Guo (D) http://orcid.org/0000-0003-2237-0494

\section{REFERENCES}

1. Guo R, Lei X, Zhang D, Liu Z, Wang X, Wei Y. Case study: the effect of running distance on the microstructure and properties of railroad axle bearings. Wear. 2018;394-395:159-165.

2. Tourret R. WE. Rolling contact fatigue-performance testing of lubricants. Int Conf Rolling-Contact Fatigue. 1976;27-38.

3. Zaretsky EVPR, Anderson WJ. NASA five-ball fatigue tester over 20 years of research. In: ASME STP771 International Conference on Rolling-Contact Fatigue Testing of Bearing Steels. 1982:5-46.

4. Ta H. Prediction of ball fatigue life in a ball/V-ring test rig. J Tribol. 1997;119(7):365-373.

5. Hampshire J, Nash J, Hollox G. Materials evaluation by flat washer testing. In: Rolling contact fatigue testing of bearing steels. Philadelphia, USA: ASTM International; 1982.
6. Zhou J, Zhu L, Chen X, Zhang P, Liu X. Design of an accelerated pure rolling contact fatigue test rig for bearing ball with three contact points. Zhongguo Jixie Gongcheng/China Mech Eng. 2004;15(7):572-574.

7. Hahn G, Bhargava V, Rubin C, Chen Q, Kim K. Analysis of the rolling contact residual stresses and cyclic plastic deformation of SAE 52100 steel ball bearings. J Tribol. 1987;109(4):618-626.

8. Bower A, Johnson K. The influence of strain hardening on cumulative plastic deformation in rolling and sliding line contact. J Mech Phys Solids. 1989;37(4):471-493.

9. Jiang Y, Sehitoglu H. Modeling of cyclic ratchetting plasticity, part I: development of constitutive relations. J Appl Mech. 1996;63(3):720-725.

10. Howell M, Hahn G, Rubin C, McDowell D. Finite element analysis of rolling contact for nonlinear kinematic hardening bearing steel. J Tribol. 1995;117(4):729-736.

11. Sakai T. Review and prospects for current studies on very high cycle fatigue of metallic materials for machine structural use. $J$ Solid Mech Mat Eng. 2009;3(3):425-439.

12. Oguma N, Lian B, Sakai T, Watanabe K, Odake Y. Long life fatigue fracture induced by interior inclusions for high carbon chromium bearing steels under rotating bending. J ASTM Int. 2010;7(9):1-9.

13. Liu X, Sun C, Hong Y. Crack initiation characteristics and fatigue property of a high-strength steel in VHCF regime under different stress ratios. Frattura ed Integritá Strutturale. 2016;35:88.

14. Littmann W. The mechanism of contact fatigue. NASA Spec Publ. 1970;237:309.

15. Bower AF. The influence of crack face friction and trapped fluid on surface initiated rolling contact fatigue cracks. J Tribol. 1988;110(4):396-399.

16. Ancellotti S, Fontanari V, Dallago M, Benedetti M. A novel experimental procedure to reproduce the load history at the crack tip produced by lubricated rolling sliding contact fatigue. Eng Fract Mech. 2018;192.

17. Li ZY, Yang B, Wu HZ, Cai BC, Inventor. An accelerated test method of rolling contact fatigue with small slip rate in metal material. 2013.

18. J Z. Study on the fatigue life of the axle box bearing for high speed train, Beijing Jiaotong University; 2014.

19. Voskamp A, Österlund R, Becker P, Vingsbo O. Gradual changes in residual stress and microstructure during contact fatigue in ball bearings. Met Technol. 1980;7(1):14-21.

20. Rancel L, Gómez M, Medina SF, Gutierrez I. Measurement of bainite packet size and its influence on cleavage fracture in a medium carbon bainitic steel. Mater Sci Eng A. 2011; 530(1):21-27.

21. Yang G, Sun X, Li Z, Li X, Yong Q. Effects of vanadium on the microstructure and mechanical properties of a high strength low alloy martensite steel. Mater Des. 2013;50(17):102-107.

22. Jiang B, Dong Z, Zhou L, Zhang C, Liu Y. Microstructural characterization and hardening mechanism of steel for large size bearing ring under fast heating and short soaking time condition. Steel Res Int. 2016;87(9):1127-1136. 
23. Jiang B, Mei Z, Zhou L, Zhang C, Liu Y. Microstructure evolution, fracture and hardening mechanisms of quenched and tempered steel for large sized bearing rings at elevated quenching temperatures. Met Mater Int. 2016;22(4):572-578.

24. Wang LM, Wang ZB, Lu K. Grain size effects on the austenitization process in a nanostructured ferritic steel. Acta Mater. 2011;59(9):3710-3719.

25. Tao NR, Wang ZB, Tong WP, Sui ML, Lu J, Lu K. An investigation of surface nanocrystallization mechanism in Fe induced by surface mechanical attrition treatment. Acta Mater. 2002;50(18):4603-4616.

26. Zhou L, Liu G, Ma XL, Lu K. Strain-induced refinement in a steel with spheroidal cementite subjected to surface mechanical attrition treatment. Acta Mater. 2008;56(1):78-87.

27. Richman R, Landgraf R. Some effects of retained austenite on the fatigue resistance of carburized steel. Metall Mater Trans A. 1975;6(5):955-964.

28. Voskamp A. Material response to rolling contact loading. ASME Trans J Tribol (ISSN 0742-4787). 1985;107:359-364.

29. Arakere N, Subhash G. Work hardening response of M50-NiL case hardened bearing steel during shakedown in rolling contact fatigue. Mater Sci Technol. 2012;28(1):34-38.

30. Xie L, Zhou Q, Wen Y, Wang L, Lu W. Microstructure variation and local plastic response of chrome molybdenum alloy steel after quasi rolling contact fatigue testing. Mater Sci Eng A. 2016;659:37-46.

31. Rycerz P, Olver A, Kadiric A. Propagation of surface initiated rolling contact fatigue cracks in bearing steel. Int J Fatigue. 2017;97:29-38.

32. Deng S, Hua L, Han X, Wei W, Huang S. Analysis of surface crack growth under rolling contact fatigue in a linear contact. Tribol Trans. 2015;58(3):432-443.

33. Grabulov A, Petrov R, Zandbergen HW. EBSD investigation of the crack initiation and TEM/FIB analyses of the microstructural changes around the cracks formed under Rolling Contact Fatigue (RCF). Int J Fatigue. 2010;32(3):576-583.

34. Okazaki S, Wada K, Matsunaga H, Endo M. The influence of static crack-opening stress on the threshold level for shearmode fatigue crack growth in bearing steels. Eng Fract Mech. 2017;174:127-138.

35. Lankford J. Initiation and early growth of fatigue cracks in high strength steel. Eng Fract Mech. 1977;9(3):617-624.

36. Li ZX, Li CS, Ren JY, Li BZ, Zhang J, Ma YQ. Effectof cold deformation on the microstructure and impact toughness during the austenitizing process of $1.0 \mathrm{C}-1.5 \mathrm{Cr}$ bearing steel. Mater Sci Eng A. 2016;674:262-269.

37. Bhadeshia HKDH, Solano-Alvarez W. Critical assessment 13: elimination of white etching matter in bearing steels. Mater Sci Technol. 2015;31(9):1011-1015.

38. Anonymous. The effect of carbide network on the life of AISI 52100 in rolling contact fatigue. Derbyshire, UK: Federal-Mogul Corporation; 1982.

39. Jiang $\mathrm{B}$, Wu $\mathrm{M}$, Zhang $\mathrm{M}$, et al. Microstructural characterization, strengthening and toughening mechanisms of a quenched and tempered steel: effect of heat treatment parameters. Mater Sci Eng A. 2017;707.

40. Everitt CM, Bo A. Contact fatigue initiation and tensile surface stresses at a point asperity which passes an elastohydrodynamic contact. Tribol Int. 2018;123:234-255. https://doi.org/10.1016/j. triboint.2017.10.013

41. Zhang W, Niu C. A linear relaxation model for shape optimization of constrained contact force problem. Comput Struct. 2018;200:53-67.

42. Walvekar AA, Sadeghi F. Rolling contact fatigue of case carburized steels. Int J Fatigue. 2017;95:264-281.

43. Smith JO. Stresses due to tangential and normal loads on an elastic solid with application to some contact stress problems. Trans Asme J Appl Mech. 1953;20.

44. Timoshenko SP. Axisymmetric stress and deformation in a solid of revolution. In: Theory of elasticity. Singapore: McGraw-Hill International Editions; 1970.

45. Wong S, Bold P, Brown M, Allen R. Fatigue crack growth rates under sequential mixed-mode I and II loading cycles. Fatigue Fract Eng Mater Struct. 2000;23(8):667-674.

46. Kaneta M, Yatsuzuka H, Murakami Y. Mechanism of crack growth in lubricated rolling/sliding contact. ASLE Trans. 1985;28(3):407-414.

47. Phillips M, Chapman C. A magnetic method for detecting the onset of surface contact fatigue. Wear. 1978;49(2):265-272.

48. Endo K, Okada T, Komai K, Morio K. Fatigue crack propagation of steel in oil. Bulletin of JSME. 1972;15(89):1316-1323.

49. Tzou JL, Hsueh CH, Evans AG, Ritchie RO. Fatigue crack propagation in oil environments-II. A model for crack closure induced by viscous fluids. Acta Metall. 1985;33(1):117-127.

50. Sih GC. Handbook of stress-intensity factors for researchers and engineers. Bethlehem: Lehigh University; 1973.

51. Cotterell B, Rice JR. Slightly curved or kinked cracks. Int J Fract. 1980;16(2):155-169.

52. Zeng X, Wei Y. Crack deflection in brittle media with heterogeneous interfaces and its application in shale fracking. $J$ Mech Phys Solids. 2017;101:235-249.

53. Erdogan F, Sih GC. On the crack extension in plates under plane loading and transverse shear. J Basic Eng. 1963;12(4):527.

54. Taira S, Tanaka K, Hoshina M. Grain size effect on crack nucleation and growth in long-life fatigue of low-carbon steel. Fatigue Mechanisms. 1979;675:135-173.

55. Mutoh Y, Radhakrishnan VM. An analysis of grain size and yield stress effects on stress at fatigue limit and threshold stress intensity factor. J Eng Mater Technol. 1981;103(3):229-233.

How to cite this article: Guo R, Yang G, Li Z, Liu Z, Wei Y. Statistical analysis on rolling contact fatigue in railroad axle bearing steel. Fatigue Fract Eng Mater Struct. 2018;1-13. https://doi.org/ $10.1111 /$ ffe. 12940 